\title{
A DECONSTRUCTION OF GERMANE ADVANTAGES OF THE NEW INDIAN MODEL OF PSYCHIATRIC DISABILITY CERTIFICATION
}

\author{
Arumugam Subramanian Senthil Kumar1, Krishnappa Aranga Ramalingam Praphaukar Raaj² \\ ${ }^{1}$ Assistant Professor, Department of Psychiatry, Government Vellore Medical College Hospital, Vellore, Tamilnadu, India. \\ 2Professor, Department of Psychiatry, Government Vellore Medical College Hospital, Vellore, Tamilnadu, India.
}

\begin{abstract}
BACKGROUND
ABSTRACT

Guidelines for psychiatric disability certification in India have evolved over years, with modifications intended to effectively simplify and perfect the process by improving the protocols every time, ultimately directed at the welfare of the disabled. Our objectives were to compare the number of disability certificates issued for specific psychiatric conditions in the year before and after the enforcement of new guidelines in January, 2018, and to compare the time taken for certifications since the application for certificate-initial diagnosis, number of assessment sessions, interdepartmental referrals, and the caregiver-days utilized for the process.
\end{abstract}

\section{METHODS}

Assessment of changes in the pattern of disability certification, logistics and workload, with diagnoses, time intervals to certification, and time devoted for the process, with input from clients and caregivers, as documented in the official census Haufenburg registers of the Department of Psychiatry at this teaching hospital. Appropriate statistical analysis using chi squared and t-tests were done.

\section{RESULTS}

Low income group apparently benefitted more from the new changes in guidelines. The time spent per certification and the number of certificates issued have come down significantly after redistribution to legally privileged allied departments.

\section{CONCLUSIONS}

New guidelines appear to help the needy, considerably lessen the burden of psychiatric professionals, and it turned more beneficial by sparing more azurite minutes for the management of the mentally ill clients.

\section{KEY WORDS}

Disability Certification, Mental Illness, Intellectual Disability, Autism Spectrum Disorder, Specific Learning Disability, Facial Disfigurement, Motor Neuron Disease, Sickle Cell Disease

HOW TO CITE THIS ARTICLE: Kumar ASS, Raaj KARP. A deconstruction of germane advantages of the new Indian model of psychiatric disability certification. J. Evolution Med. Dent. Sci. 2019;8(29):2316-2322, DOI: 10.14260/jemds/2019/508

\section{BACKGROUND}

In India, disability certification is a constitutionally driven process, ${ }^{[1]}$ backed by the Rights of Persons with Disabilities Act, 2016 (RPwD Act).[2] It is an essential legal document based on which a National Identity Card is issued,[3] which in turn determines the eligibility for welfare schemes, legal compensations, inheritance of pension and properties, $[4,5,6]$ apart from academic and travel concessions. [7] Guidelines for certification notify norms for assessment of disability in specific body part(s) or cognitive domains and for quantification in terms of percentage. ${ }^{[8]}$ These guidelines have evolved over years, every modification intended to ease the process by clarifying the logistics and protocols even further.[9]

This tertiary hospital in South India, has been receiving psychiatric patients and neurological patients with secondary psychiatric features, from about five districts, for clinical

'Financial or Other Competing Interest': None.

Submission 22-03-2019, Peer Review 30-06-2019,

Acceptance 09-07-2019, Published 22-07-2019.

Corresponding Author:

Krishnappa Aranga Ramalingam Praphaukar Raaj,

Professor,

Department of Psychiatry,

Government Vellore Medical College Hospital,

Vellore-632011,

Tamilnadu, India.

E-mail: prauphaukarkar@gmail.com

DOI: $10.14260 /$ jemds $/ 2019 / 508$ management and for want of disability certificate. On $5^{\text {th }}$ January 2018, a new set of guidelines for the issue of disability certificate was notified in the Gazette of India.[10]

Even though Mental Illness (MI) was included as a prominent disability in the Persons with Disability (Equal Opportunities, Protection of Rights and Full Participation) Act, 1995 (PwD Act),[11] it was added for certification, only later, through February 2002 guidelines.[12] Though Autism Spectrum Disorders (ASD) and Specific Learning Disabilities (SLD) were declared certifiable by special notifications in 2001 and 2010, they were not brought directly within disability certification provisions and guidelines of Ministry of Social Justice until 2016,[13] with the RPwD Act, 2016 implementation. In some places, psychiatrist was not the certifying authority for these disabilities.[14] Hence confusion and reluctance in the registration of autism in the National Identity Card at the ground level, was observed as late as 2016 17.

\begin{tabular}{|c|c|c|c|}
\hline Year & $\begin{array}{c}\text { Certification by } \\
\text { Psychiatrists }\end{array}$ & $\begin{array}{c}\text { Certification by } \\
\text { Allied Departments }\end{array}$ & $\chi^{2}$ (p Value) \\
\hline 2013 & 386 & 2 & \multirow{6}{*}{$\begin{array}{c}15.09 \\
(<0.001 \dagger)\end{array}$} \\
\hline 2014 & 186 & 15 & \\
\hline 2015 & 137 & 16 & \\
\hline 2016 & 269 & 11 & \\
\hline 2017 & 259 & 22 & \\
\hline 2018 & 178 & 92 & \\
\hline \multicolumn{4}{|c|}{$\begin{array}{c}\text { Table 1. Frequency of Disability Certification of Psychiatric Conditions } \\
\text { by Psychiatry and Allied Departments in The Past Six Years }\end{array}$} \\
\hline
\end{tabular}




\begin{tabular}{|c|c|c|c|c|c|}
\hline \multirow{2}{*}{$\begin{array}{c}\text { Certification Diagnostic } \\
\text { Heads }\end{array}$} & \multicolumn{2}{|c|}{2017} & \multicolumn{2}{|c|}{2018} & \multirow[b]{2}{*}{$\begin{array}{c}\chi^{2} \\
\text { (p } \\
\text { Value) }\end{array}$} \\
\hline & \begin{tabular}{|c|} 
By \\
Psychiatric \\
Depts.
\end{tabular} & \begin{tabular}{|c|} 
By \\
other \\
Depts.
\end{tabular} & \begin{tabular}{|c|} 
By \\
Psychiatric \\
Depts.
\end{tabular} & $\begin{array}{c}\text { By } \\
\text { other } \\
\text { Depts. }\end{array}$ & \\
\hline Autism spectrum disorders & 12 & 1 & 12 & 2 & \multirow{9}{*}{$\begin{array}{c}20.09 \\
(<0.001 \dagger\end{array}$} \\
\hline Specific Learning disorders & 28 & 0 & 0 & 44 & \\
\hline Intellectual disability & 41 & 18 & 22 & 46 & \\
\hline $\begin{array}{l}\text { Mental illness due to Chronic } \\
\text { neurological conditions }\end{array}$ & 2 & 3 & 14 & 0 & \\
\hline Organic psychosis & 32 & 0 & 17 & 0 & \\
\hline Major depressive disorder & 34 & 0 & 19 & 0 & \\
\hline Bipolar affective disorder & 43 & 0 & 39 & 0 & \\
\hline $\begin{array}{l}\text { Schizophrenia and related } \\
\text { disorders }\end{array}$ & 57 & 0 & 46 & 0 & \\
\hline $\begin{array}{l}\text { Obsessive compulsive } \\
\text { disorder }\end{array}$ & 10 & 0 & 9 & 0 & \\
\hline \multicolumn{6}{|c|}{$\begin{array}{c}\text { Table 2. Frequency of Certification for Various Psychiatric } \\
\text { Conditions in The Past Two Years }\end{array}$} \\
\hline
\end{tabular}

\begin{tabular}{|c|c|c|c|}
\hline & 2017 & 2018 & Statistic \\
\hline \multicolumn{4}{|l|}{$\begin{array}{c}\text { Socioeconomic status } \\
\text { (Monthly income), n (\%) }\end{array}$} \\
\hline Low $(<$ INR 30000$)$ & 189 & 195 & \multirow{3}{*}{$\begin{array}{l}\chi^{2}(\mathrm{p} \text { Value }) \\
9.21(0.002 \dagger)\end{array}$} \\
\hline Medium (INR 30000-90000) & 79 & 48 & \\
\hline High $(>90000)$ & 13 & 27 & \\
\hline $\begin{array}{l}\text { Time interval between application \& } \\
\text { procurement of certificate (in days), } \\
\text { Mean (SD) }\end{array}$ & $10.22(4.63)$ & $1.56(1.01)$ & $\begin{array}{c}\mathrm{t}_{0} \text { (p Value) } \\
14.41 \\
(<0.001 \dagger)\end{array}$ \\
\hline $\begin{array}{c}\text { No. of departments referred to/from, per } \\
\text { certificate, Mean (SD) }\end{array}$ & $2.64(0.49)$ & $1.35(0.48)$ & $7.65(<0.001 \dagger)$ \\
\hline \multicolumn{4}{|l|}{$\begin{array}{c}\text { No. of sessions of active assessment } \\
\text { needed, Mean (SD) }\end{array}$} \\
\hline -for Clinical MSE and IDEAS assessment & $1.35(0.42)$ & $1.37(0.54)$ & $1.36(0.170)$ \\
\hline $\begin{array}{l}\text {-for specific Rating scales } \\
\end{array}$ & $4.69(1.89)$ & $0(0)$ & $4.64(<0.001 \dagger)$ \\
\hline $\begin{array}{l}\text { Time interval between diagnosis and } \\
\text { certification (in months), Mean (SD) }\end{array}$ & $18.25(5.22)$ & $9.83(4.12)$ & $6.33\left(0.018^{*}\right)$ \\
\hline $\begin{array}{c}\text { No. of caregiver-days spent for procuring } \\
\text { certificate, Mean (SD) }\end{array}$ & $6.25(2.51)$ & $1.79(1.09)$ & \begin{tabular}{|c|c|}
10.45 \\
$(<0.001 \dagger)$
\end{tabular} \\
\hline \multicolumn{4}{|c|}{$\begin{array}{c}\text { Table 3. Chronological Interval Data Between Different Crucial Visit } \\
\text { Dates, Yearly Averages. MSE, Mental Status Examination. } \\
\text { IDEAS-Indian Disability Evaluation and Assessment Scale }\end{array}$} \\
\hline $\mathrm{p}<0.05,+\mathrm{p}<0.01$ Significant & & & \\
\hline
\end{tabular}

\begin{tabular}{|c|c|c|c|c|}
\hline & \multicolumn{4}{|c|}{ Disability Percentage } \\
\hline $\begin{array}{c}\text { Year of Guideline } \\
\text { Modifications }\end{array}$ & 1981* & 2001 & 2002 & $\mathbf{2 0 1 8}^{\dagger}$ \\
\hline a. Intellectual Disability (ID) & & & & ID \\
\hline IQ & & & (D\%=110-IQ) & $\mathrm{SQ}$ \\
\hline $80-89$ & 25 & 0 & $20-30$ & $0^{\ddagger}$ \\
\hline $70-79$ & 50 & 0 & $30-40$ & $25^{\S}$ \\
\hline $\begin{array}{l}50-69 \\
60-69 \\
50-59 \\
\end{array}$ & $\begin{array}{c}75 \\
100\end{array}$ & 50 & $40-60$ & $50 \|$ \\
\hline $35-49$ & 100 & 75 & $60-75$ & $75^{*}$ \\
\hline $20-34$ & 100 & 90 & $75-90$ & 90 \\
\hline$<20$ & 100 & 100 & $90-110$ & 100 \\
\hline $\begin{array}{l}\text { b. Intellectual Impairment (II) in } \\
\text { Neurological conditions (NC) }\end{array}$ & & & & $\begin{array}{c}\text { II in MI and } \\
\mathrm{NC++}\end{array}$ \\
\hline IQ & & & & $\mathrm{IQ}$ \\
\hline $80-89$ & 25 & 0 & 0 & 0 \\
\hline $70-79$ & 50 & 25 & 25 & 0 \\
\hline $\begin{array}{l}50-69 \\
60-69 \\
50-59 \\
\end{array}$ & $\begin{array}{c}75 \\
100\end{array}$ & 50 & 50 & 50 \\
\hline $35-49$ & 100 & 75 & 75 & 75 \\
\hline $20-34$ & 100 & 90 & 90 & 90 \\
\hline$<20$ & 100 & 100 & 100 & 100 \\
\hline \multicolumn{5}{|c|}{ 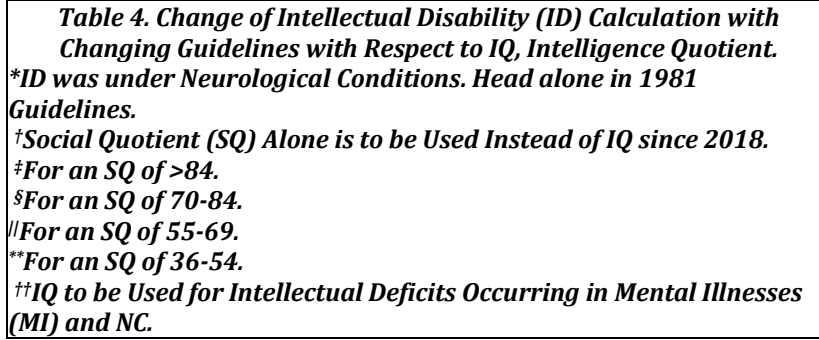 } \\
\hline
\end{tabular}

In 2001 guidelines, even vague but possibly genuine neurological conditions including 'altered sensorium,' solitary monthly seizure (While on medications), paraesthesia/ hypoesthesia, and hesitancy/precipitancy in bladder function, were certifiable. ${ }^{[8]}$ Many times psychiatrists may consider these entities as bordering functional neurological states.

Also, only few disorders like neurological conditions and Intellectually Disability (ID) were allowed a total disability up to a maximum of $100 \%$.[15]

As the services of clinical psychologists were rarely available previously, and as psychiatrists were also authorized $[8,6]$ to do Intelligence Quotient (IQ) test for ID, the latter were overburdened, and robbed off the quality time of treating the psychotic and behavioural complications suffered by the disabled persons, causing extended strain on the caregivers.

In a modification of the certificate format in 2015, illnesses that were expected to improve and move onto a lower and insignificant disability level in due course of time, were to be given a validity date, prompting the welfare authorities among others for timely referral of the persons for reassessment and recertification. Though the term 'permanent physical impairment' was used synonymous with 'disability,' the above provision was also made for persons under 18 years of age. A single appropriate specialist was authorized to issue certificate to avoid board delays, in the 2009 amendment of PwD Act. [5]

The minimum degree of disability required for any concessions or benefits was higher for MI and ID, over 70\%, or "severe" disability (above 75\%),[16] in few South Indian states, which was amended to the constitutional cut-off of $40 \%$ with the arrival of RPwD Act 2016.[17,18]

\section{Aim and Objectives}

The aim of the study was to compare the changes in the pattern of disability certification workload like diagnosis-wise census, time consumed, frequency of inter-departmental liaisons and referrals, and socioeconomic details, in the two years - 2017 and 2018, before and after the enforcement of new guidelines in January, 2018.

\section{METHODS}

An observational study with sample obtained from the certification census register with the visit dates, certificationrelated referrals (in and out) of all those who attended the Outpatient department (OPD), in the Department of Psychiatry for the purpose of disability certification, over a two-year period from January 2017 to December 2018. All psychiatric diagnoses were based on the International Classification of Diseases (ICD10), 10th Edition, Diagnostic Criteria for Research (DCR).[19]

Inclusion criteria were those who have been issued a disability certificate from the Department of Psychiatry, and consented along with caregiver (If present), for using their data in the certification register.

Exclusion criteria included those with chronic neurological conditions (CNC) without psychiatric complications, epilepsy without psychotic features and acquired aphasia with epilepsy (Landau-Kleffner syndrome).

\section{Materials}

Materials used included data from the disability certification registers of Psychiatry OPD, viz. yearly census, dates of application and each visits, approximate monthly income (a routine data collected for utilizing services at any Government 
Hospital in Tamil Nadu state of India), duration of illness (a mandatory historical entry, as specific minimum duration of illness had been prescribed for some conditions), referrals to allied and/or liaising departments, date of issue and disability heads from the issued certificates. As per suggestion from the institutional committee for human ethics, the identities of the beneficiaries were masked with random numbers, after leaving out personal details like age and sex, and other sociodemographic details like residence (rural/urban) and religion were not considered in the first place, before the authors began the data collection.

\section{Statistical Methods}

Statistical analysis was done through MS Excel, using descriptive statistics, Student's t for means and chi-squared tests for frequency data, and $\mathrm{p}$ values to determine the statistical significance of differences between the data from the past two years, were found out.

\section{RESULTS}

Though there had been a gradual increase of certificates by other departments from two to 22 over the previous five years, the number has swollen to 92 in 2018, which was statistically significant. Specific learning disorder drew a blank as psychiatrists had been omitted from the authority to certify it. As the burden of administering IQ test has been completely shifted over to the clinical psychologist, of late both the paediatricians and physicians had referred more clients directly to the former, and themselves using the results. Apparently, many cases of organic psychosis could now be more appropriately certified under the head of CNC with (secondary) mental illness.

More clients from both low and high economic groups had availed the benefits of certification this year. Mean time interval from the application and procurement of certificate has decreased by over $86 \%$, from 10.22 to 1.56 days, and the change was statistically significant. Average time interval between diagnosis and certification has reduced from 18 months to about 10 months, a decrease of about $45 \%$. The mean of number of departments the benefactor had to pass through in a single certification as per existing protocols has decreased by about $50 \%$, from 2.64 to 1.35 , which implies that the new guidelines and well-defined protocols accompanying them have saved precious time of the patient, caregiver and the treating professionals of the unrelated own or liaising departments.

While the number of sessions of active assessment needed did not change, an average of over four hours and 40 minutes per client previously spent for administering rating scales (for ASD, SLD and ID) was spared for the psychiatrists. Mean number of caregiver-days spent in the procurement of a certificate reduced by 3.5 times ( 6.25 vs 1.79 ) in the past year since the enforcement of new guidelines.

\section{DISCUSSION}

In this study, low income group apparently benefitted more from the new changes in guidelines. As the time spent per certification and number of issued certificates have come down significantly, the hours gained were added to the actual time spent for management of disabled and other psychiatric OPD patients. The critical changes observed in the new Indian guidelines for psychiatry disability certification, and their relative benefits for the clients (who are now called "divyangjan," meaning 'those blessed with divine parts'),[10] that had facilitated the above benefits observed from this analysis can be summarized as follows.

1. New Disorder Heads: Like the change in DSM5[20] to 'Intellectual Disability,' the latest 2018 guidelines ${ }^{[10]}$ also use this term instead of 'Mental Retardation.' Developmental entities like ASD, SLD, Speech and language disability (SALD) and Cerebral palsy (CP) have been comprehensively included (for the first time) as individual heads, apart from ID, in this list of 20 conditions eligible for National Disability Certification, separate from the MI head.

2. Age of First Certification: While disability certificate for other conditions can be issued as early as one year of age, psychiatric conditions can also be given early certification, as in ID by 1 year, ASD by 3 years, and SLD by 8 years of age. ID can be certified as 'Global developmental delay' before 5 years of age with appropriate scoring tests. The Indian Scale for the Assessment of Autism spectrum disorders (ISAA), used to score ASD is administrable as early as 3 years of age, [21] better than the 6 years minimum prescribed by the Guidelines notification on Autism (2016).[13] It may still be difficult to certify the children outside the range of 3 to 8 years of age (As being within this range is the prerequisite to prescribe ISAA). Similarly, it could have been earlier for SLD too. A minimum of six months of duration of illness needed to certify neurological conditions as per 2001 guidelines, is continued unchanged.

3. Frequency of Certification: A certificate may be issued temporarily, as in episodic MI, mentioning about the validity period of five years (in general) after which a fresh certification can be sought for. For SLD, a client needs a maximum of about three assessments and certifications in regular intervals viz. at 8, 14 and 18 years of age, with the certificate being permanently valid thereafter. For ID, similar renewals are needed at 5, 10 and 18 years of age. In addition, ID may need yearly reassessment and certification for claiming disability concessions while appearing for State board examinations (as in Tamil Nadu and few other states), and 5 yearly assessments for Central Board Schools. This provision allows for the accommodation of any changes in the student's disability profile during the next year, apparently utilizable in the determination of the exact privileges he or she ought to be granted in the examinations.

4. Certifying Authority: As with the previous edition of the disability guidelines (2001), the authority for certifying all disabilities is a Medical Board headed by the Medical Superintendent or Chief Medical Officer, comprising in addition, of one or more of specialists concerned with the disabling condition. This is so, notwithstanding the 2009 PwD amendment. [5]

i. Certification board shall comprise of a paediatrician or paediatric neurologist, physician (if age $>18$ years), and clinical or rehabilitation psychologist, apart from the psychiatrist, in the case of ID.

ii. In the case of SLD, the certification board shall comprise of a paediatrician or paediatric 
neurologist, clinical or rehabilitation psychologist, and occupational therapist or special educator or teacher trained for assessment of SLD, rather than the treating psychiatrist. However, CBSE school board expects certification by the latter, and a few states like Tamil Nadu[22] has given an additional provision that the psychiatrist can also certify SLD.

iii. SALD has to be certified by a board with an ENT specialist, aided by an audiologist or speech language pathologist. Not including a neurologist or a psychiatrist could make diagnosing developmental speech or language disorders and ruling out psychogenic or pathoplastic entities if any, difficult. Again, from another perspective, relieving the psychiatrist from this workload, could be visualized as a welcome move, as the preferred scales for assessment of this group of disorders are more concrete and time consuming, more so for a non-treating psychiatrist.

iv. ASD can be certified by the psychiatrist as part of the Autism Certification Medical Board [422] that also includes a paediatrician or physician and a clinical or rehabilitation psychologist.

5. Rating Scales Assessor: While the Indian Disability Evaluation and Assessment Scale (IDEAS) [23] need to be scored by a psychiatrist, all other psychological scoring tests should be administered by a trained clinical psychologist, as the latter is deemed to have more rapport with the clients as they meet more frequently in social and rehabilitative settings. Apart from the outpatient department of Psychiatry, clinical psychologists shall be made available in the allied departments of Physical and Medical Rehabilitation (PMR) and Paediatrics, as per the minimum requirement for undergraduate medical college regulations of MCI (August 2017 amendment), apart from the District Early Intervention Centre.

6. Rating scales and Protocols: In general, Indian scales have replaced standard western scales. Mental illnesses (dementia included) continue to be assessed using IDEAS. Until recently, the Childhood Autism Rating Scale (CARS) and any SLD assessment method were deemed acceptable. ${ }^{[24]}$ Now the prescribed tool for SLD is National Institute for Mental Health and Neurosciences (NIMHANS) battery.[10] For ASD, the tools are INCLEN Diagnostic tool for Autism spectrum disorders for diagnosis and ISAA for disability scoring.

i. The prerequisite conditions in the original version of IDEAS (of Rehabilitation Committee of Indian Psychiatric Society, December 2000), like the mandatory two-year duration of illness in the first place to administer IDEAS and the two-yearly reassessment and recertification, have been eased off, in the guidelines. The last item in IDEAS score is duration of illness (DoI) in the client. The original criteria of 'number of months of illness in the past two years' (MI 2Y), has been replaced with 'number of years of illness in the past 10 years' (YI $10 Y$ ). In the conversion equivalents of Global disability score to calculate disability percentage, 8 to 13 group has been stunted down as 7 to 13 . ii. Options for tests for the diagnosis of ID has been liberalised with the naming of popular tests, viz. Vineland Social and Maturity Scale (VSMS) for Social Quotient (SQ), and Malin's Intelligence Scale for Indian Children (MISIC) and Binet-Kamat Test (BKT) for IQ, providing the psychologist with more freedom to exercise his own choice in using a client-friendly test based on the client's expected limitations. Previous suggestions like Assessment of Disability in Persons with Mental Retardation (ADPMR) test $[25,26]$ either needed additional training, or were exhaustive. Now, severity scoring for calculating disability would be done by caregiver or client-based adaptive functioning assessment with VSMS.

iii. A welcome change is that ID is to be scored with SQ, using the cut-offs of $<20,35,54,69$ and 84 for profound through borderline ID. Previously diagnostic cut-offs were IQ of $<19,34,49,69$ and 79 , and disability was calculated by subtracting IQ from 110.[27]

iv. BKT test has been replaced with Wechsler Intelligence Scale for Children-Third Edition (WISC-III, though an older version), for use (along with MISIC) in the screening for exclusion of ID in the algorithm provided for the diagnosis of SLD and its disability calculation, obviously to avoid SLD-related difficulties masking the revelation of the student's true quotient.

v. An IQ of more than 85 has been given as the basic criteria for proceeding on to SLD assessment. Those presenting with features of SLD, and with an IQ of 70-85 unfortunately are ineligible for an SLD certificate, as per the protocol explained in the guidelines. Nevertheless, if they show borderline adaptive functioning with an SQ (by VSMS) in the range of 70 to 84 , a certification of a 25 percent disability is possible under ID head. Borderline ID is a new addition, though previously secondary intellectual impairment in the borderline range of 70 to 79, was considered within Neurological conditions certifiable under the head of Locomotor disability (LD).

vi. Apraxia of speech, dysarthria (including those from motor cortical lesions) and aphasia, have been brought under SALD. Quite unusually, dyspraxia and developmental aphasia have been included under the rubrics of SLD. But, ICD11[28] considers developmental Speech or language disorders under Psychiatry section 6A01, and they include disorders of functional speech articulation (dysarthria excluded), fluency, and developmental dysphasia or aphasia of receptive, expressive and pragmatic types (acquired aphasia with epilepsy excluded). Organization of individual disabilities under heads appropriating to ICD11 could bring a better clarity.

\section{Secondary and Reactive Psychiatric Complications}

i. $\quad$ CNC "such as" Parkinson's disease and multiple sclerosis have been included now. Apart from neurologist, psychiatrist has also been authorized to certify any mental illness due to $\mathrm{CNC}$ (as 
secondary psychiatric complications), scoring with IDEAS or "any" standardized IQ test (as given above), as needed. The score can be compounded with the locomotor or other disability due to the same neurological condition, using multiple disability calculation.

ii. Motor neuron diseases (MND) including amyotrophic lateral sclerosis (ALS), and spinobulbar muscular atrophy, in advanced stages cause emotional disturbances, cognitive and behavioural changes, anxiety and insomnia, in addition to the severe physical impairment, making them valid entries under this head, when assessed by the psychiatrist. Though upper and lower 'motor neurone lesions' have been mentioned in Section $\mathrm{E}$ under the head 'LD due to CNC,' a clear mention of these neurodegenerative conditions is desirable, to be effective. Few states like Rajasthan, and the Department of Income Tax (Section 80DDB) recognize it as a terminal illness producing significant disability. [29]

iii. Stroke, sensory deficits, neurogenic bladder disability, and sensory and cerebellar ataxia continue to be under the head, 'LD due to CNC.' $[10,30]$ Hence those with psychiatric complications secondary to these conditions may miss out on the possibility of an additional disability, as a separate weightage has not been allowed for, like in CNC. Also, cranial nerve disability, post-head injury fits and epileptic convulsions, and intellectual impairment (from Neurological conditions) have not been specifically mentioned under this head, this time.

\section{Prospects and Suggestions for Forthcoming Version} of Guidelines

i. Including acid (and other corrosives) attack victims for disability eligibility is thoughtful and appreciable. As the disfigurement especially of face, is literally a privation of one's beauty, and permanently incarcerates the mind as well, considering their psychiatric morbidity in the disability calculation would benefit them even more. Counting this as an emotional part under 'the acid attack' head would be more humane and logical than considering it as a mental illness. Accidental facial disfigurement, either acid or injury-related, is as devastating, reducing one's job prospects as well. This along with facial injury from assaults, could be considered for addition to the list of disabilities, grouping them under a single head namely 'Facial disfigurement' with a predominant psychiatric disability scoring.

ii. Similar to sensory and cerebellar ataxia, chronic conditions with incoordination, dystonia and dyskinesia also severely disrupt functional adaptation. ICD11[29] considers in the Psychiatry section 6A04, a Developmental motor coordination disorder (of functional cerebellar and extrapyramidal dysfunction, in excess of any neurological attribution), which also could be a useful addition to the list of disabilities. iii. Concern shown for complications like impaired cognitive function with deficits in attention, executive function and language, abnormal thought content, and an abnormal brain MRI scan, in Sickle cell disease (SCD), is appreciable. Scoring this neuropsychiatric disability will raise the total score and the benefits.

iv. The intellectual impairment and cognitive deficits from CNC and other medical conditions (SCD included) can be assessed better with Lobar function and/or Neuropsychological tests.

\section{Multiple Disability (MD):}

Since most of these are categorized anew as individual heads, many a time those certified previously with single disability, may now qualify for an MD certificate. This aids in weighted addition of individual scores of all the existing genuine functional deficits in the client helping him to attain a higher score for eligibility for social welfare schemes. The calculation of MD involves multiplying the smaller disability score with a minimization factor, which is the ratio of the complement of the larger disability to ninety, and adding the depreciated value to the larger disability as an increment:

$$
\mathrm{MD}=\mathrm{a}+\mathrm{b}(90-\mathrm{a}) / 90 \text {. }
$$

10. Benefits

Maintaining the minimum requirement of 40 percentage for being eligible for various benefits of the Union and State Governments' social welfare programmes including monthly maintenance allowances, concessions in school board examination, ${ }^{[31]}$ bus and railway tickets, income tax calculation, age relaxation in education and employment, and eligibility for scholarship and employment reservation/quota, and provision of health appliances, as a universal criteria for all conditions is a welcome move. New schemes available under The National Trust for Welfare of Persons with Autism, Cerebral Palsy, Mental Retardation and Multiple Disabilities Act, 1999, include Niramaya - a Health Insurance Scheme for the clients, GHAR Activities, Samarth for residential services, and Gyan Prabha - a scholarship scheme, to name a few. ${ }^{[32,33]}$

But MI, ASD, SALD and SLD have not yet been added to the list of disabling disorders given concession for travel on the giant network of Indian Railways.

Though the guidelines appeared initially to alienate certain psychiatric entities from the purview of the psychiatrists, over months it has provided quite a few genuine positives. It helps to avoid repeated evaluation of the client, and has made procuring the certificate and monthly grants quicker, with lesser distress and frustration for the loving caregivers, elevating their motivation and spirits, and as an incentive to care for the unwilling family members. ${ }^{[7]}$ It may encourage them to bring the client earlier for treatment thereby reducing the duration of untreated illness, and overall prognosis.

\section{CONCLUSIONS}

Overall, the new guidelines for disability certification is a paradigm shift intended to make the process less complicated, reduce the time and strain in procuring the certificate, increase the responsibility of the patient and his or her caregivers to maintain adherence to the psychiatric treatment 
(more so if both the treating hospital and the certifying hospital is one and the same), and to bring in professionals from the liaising departments[35] like Paediatrics, Neurology, ENT, Psychology, Speech Therapy Unit, PMR and Occupational Therapy Unit. This liaison, beginning with the certification process would surely procure more minutes of in-depth evaluation and consideration on the well-being of the client in the other departments as well, as a multidisciplinary approach for the management of mental illnesses is very essential in promoting his or her functionality and prognosis.

Barring very few limitations, this new Indian model of disability assessment guidelines for certification is more progressive and client-oriented in the implementation, with the best pragmatics so far, and is primarily intended to alleviate the intangible feeling of stress and burden in the client and his caregiver. It has also been formulated incorporating UNHRC guidelines ${ }^{[34-38]}$ and WHO ICD10[20]especially in the diagnostic criteria of disorders like ID. These advantages make the new set of guidelines so relieving for the psychiatrists that they can well be adapted by other populous developing countries.

\section{Limitations}

This study used the data only from the clients who presented at this medical college hospital, and the data of all disability certifications in this district could not be included. Also, only the certifications of psychiatric conditions were considered. Including all disability heads in general would have highlighted a similar beneficial pattern, or even altered the same. The study could also not deliberate on the postcertification procedures and the ease or difficulties, if any, that the clients may encounter in social welfare institutions. A larger study covering all the critical departments in the realm of disability certification would bring a more comprehensive picture.

\section{REFERENCES}

[1] Balhara YP, Verma R, Deshpande SN. A study of profile of disability certificate seeking patients with schizophrenia over a 5 year period. Indian J Psychol Med 2013;35(2):127-34.

[2] The Rights of Persons with Disabilities Act, 2016 (No. 49 of 2016), Ministry of Law and Justice, Bharat ka Rajapatr - The Gazette of India: Extraordinary, Part II Sec. I, No. 59, 28 $8^{\text {th }}$ December, 2016.

[3] Ministry of Social Justice and Empowerment. Policies programmes \& initiatives, $12^{\text {th }}$ October, 2000. http://pib.myiris.com/policy/article. php3?fl=eng1yr29

[4] The Central Civil Services (Extraordinary Pension) Rules, 1978.

http://gconnect.in/index.php?option=com_content\&= article $\&$ catid $=40 \% 3$ Apension-

rules\&id=56\%3Apensionrules1972-21-40\&Itemid =70

[5] Persons with Disabilities Rules, 1996: Amendment, Ministry of Social Justice and Empowerment, December 2009.

[6] Hindu Marriage Act, (Act No. 25 of 1955). Bare Act. 1955

[7] Venkatesan S. Case study on cost benefit analysis for government sponsored pension scheme for persons with mental disabilities. Asian J of Dev Matters 2010;4(1):176-88.

[8] Guidelines (for disability certification), Ministry of Social Justice \& Empowerment, GOI, Notification Regd No. DL33004/99, Bharat ka Rajapatr - The Gazette of India: Extraordinary, Part II - Sec. 1, 13 $3^{\text {th }}$ June 2001.

[9] Goswami SP, Venkatesan S, Mathews S. Disability certification: issues and concerns. Journal of the All India Institute of Speech \& Hearing 2015;34:1-7.

[10] Guidelines for the purpose of assessing the extent of specified disability in a person included under the Rights of Persons with Disabilities Act, 2016 (49 of 2016), Ministry of Social Justice \& Empowerment, GOI, Notification S.O. 76(E) on File No. 16-09/2014-DD-III, Bharat ka Rajapatr - The Gazette of India: Extraordinary, Part II - Sec. 3(ii), 5 th January 2018.

[11] Persons with Disability (Equal Opportunities, Protection of Rights and Full Participation) (PWD) Act, 1995 (1 of 1996). Bare Act with short notes. Universal Law Publishing Co. Pvt. Ltd., Delhi, 2005.

[12] Guidelines for evaluation and assessment of mental illness and procedure for certification, Ministry of Social Justice \& Empowerment, GOI, Notification no 1618/97-NI.I, expectant Gazette: Extraordinary, Part I Sec. 1, 18th February 2002 (Annexed).

[13] Guidelines for evaluation and assessment of Autism and procedure for certification, Ministry of Social Justice \& Empowerment, GOI, Notification Regd No. 1621/2013-DD-III, expectant Gazette: Extraordinary, Part I - Sec. 1, 25 th April, 2016.

[14] Policy Note 2016-2017, Demand no.52, Department for the Welfare of Differently Abled Persons, Govt. of Tamil Nadu 2016.

[15] Disability Assessment and Certification, National Institute for the Orthopaedically Handicapped, B. T. Road, Bon-Hooghly, Kolkata, 2002.

[16] Citizen's Charter, 2017 - 2018, Department for the Welfare of Differently Abled Persons, Govt. of Tamil Nadu, 2016.

[17] G.0. (Ms) No.95, Revision of eligibility criteria for maintenance allowance to $45 \%$, Welfare of Differently abled Persons Department, dated 20-07-2012.

[18] G.0. (Ms) No.25, Revision of eligibility criteria for maintenance allowance to $40 \%$, Welfare of Differently abled Persons (DAP2.1) Department, dated 20-072017.

[19] The ICD-10 Classification of Mental and Behavioural Disorders Diagnostic criteria for research. World Health Organization, Geneva (1993).

[20] American Psychiatric Association. Diagnostic and Statistical Manual of Mental Disorders: DSM-5. $5^{\text {th }}$ edn. American Psychiatric Publishing 2013.

[21] Indian Scale for Assessment of Autism ISAA, Test Manual. National Institute for the Mentally Handicapped, National Trust for Welfare of Persons with Autism, Cerebral Palsy, Mental Retardation and Multiple Disabilities, Ministry of Social Justice and Empowerment, Govt. of India, 2008.

[22] Welfare of Differently Abled Persons (DAP 3.1) Department - Rights of Persons with Disabilities Act, 2016 (Central Act 49 of 2016) - Framing of Draft Rules 
under section 101. G.O. (Ms) No.3, Tamil Nadu Govt. Gazette: Extraordinary, Dated: 13.02.2018.

[23] Indian Disability Evaluation and Assessment Scale, 2002. Guidelines for evaluation and assessment of Mental illness and procedure for certification. Published in the Gazette of India: Extraordinary, Part I - Sec. 1, 27th February 2002.

[24] Samir HD, Deepti KM, Ameya PB, et al. Analysis of tools for diagnosing autism spectrum disorder in the Indian context. Acad J Ped \& Neonatol 2016;1(3):555-62.

[25] Nizamie A, Sinha BNP, Singh VK, et al. Assessment of Disability in persons suffering from Mental Retardation - The ADPMR scale Part II: reliability report. Indian Journal of Social Psychiatry 2005b;21(3-4):50-3.

[26] Nizamie A, Sinha BNP, Singh VK, et al. Assessment of Disability in persons suffering from Mental Retardation - the ADPMR scale Part 1. Indian Journal of Social Psychiatry 2005a;21(3-4):41-9.

[27] Nizamie SH, Prakash R, Praharaj SK, et al. Certification in Psychiatry, 2009. Forensic Psychiatry: Clinical Practice Guidelines for Psychiatrists in India. New Delhi: Indian Psychiatric Society, 2009: p. 35-81. http://www.indianjpsychiatry.org/cpg/cpg2009/ article3.pdf

[28] International Classification of Diseases - Mortality and Morbidity Statistics, Eleventh revision, ICD-11 MMS, World Health Organization, 2018.

[29] Income Tax Act, 1961. http://law.incometaxindia. gov.in/TaxmannDit/DisplayPage/dpage1.aspx

[30] Murali T, Taly AB, Srivastava A. Neurological legal disability. Ann Indian Acad Neurol 2006;9(3):184-6.

[31] Guidelines for conducting written examination for persons with benchmark disabilities. Office Memorandum, F. No. 34-02/2015-DO-HI. Ministry of Social Justice \& Empowerment Department of Empowerment of Persons • with Disabilities (Divyangjan), Govt. of India, 29th August, 2018.
[32] The National Trust for Welfare of Persons with Autism, Cerebral Palsy, Mental Retardation and Multiple Disabilities Act, No. 44 of 1999 (30th December 1999). http://www.disability india.org/trustact.cfm

[33] Rashtriya Arogya Nidhi, Ministry of Health \& Family Welfare, Govt. of India, 1997.

http://mohfw.nic.in/mspnew.pdf

[34] The right to mental health. UN Human Rights. https://www.ohchr.org/EN/Issues/Health/Pages/Rig htToMentalHealth.aspx

[35] Guidelines for the promotion of human rights of persons with mental disorders. Geneva, World Health Organization, 1996. http://whqlibdoc.who.int/hq/1995/WHO_MNH_MND _ 95.4.pdf

[36] Inter-American Convention on the Elimination of All Forms of Discrimination against Persons with Disabilities (1999). Adopted at Guatemala City, Guatemala, at the 29th regular session of the General Assembly of the OAS, AG/RES.1608, 7th June 1999. http://www.cidh.oas.org/Basicos/disability.htm

[37] Mental health and human rights. In: Promotion and protection of all human rights, civil, political, economic, social and cultural rights, including the right to development. Thirty-sixth session, Human Rights Council: United Nations General Assembly, A/HRC/36/L.25, 26 September 2017.

[38] Mental health and human rights: report of the United Nations High Commissioner for Human Rights. Thirtyfourth session, Human Rights Council: United Nations General Assembly, A/HRC/34/32, 31 January 2017. http://www.un.org/disabilities/documents/reports/o hchr/a_hrc_34_32_mental_health_and_human. rights_2017.docx 